\title{
Prevalence of Transfusion Transmitted Infections among Blood Donors at a Tertiary care Teaching Hospital in Southern Rajasthan
}

\author{
Preeti Agrawal*, Suraj Jain, Sajjan S.Surana and Sashi Sujanani \\ Department of Pathology, Pacific Medical College and Hospital, Udaipur, Rajasthan, India
}

\begin{abstract}
Background: Safe blood transfusion is of utmost importance as an unsafe blood transfusion bears lot of burden on human life and economy. Amongst the blood transfusion complications, transmission of certain infections like HIV, Hepatitis B, Hepatitis C and Syphilis are most significant for the long term detrimental side effects. The present study was carried out with an aim to assess the trend and seroprevalence of transfusion transmitted infections (TTIs) among blood donors at our blood bank.

Methods: The present retrospective study was carried out at blood bank attached to Pacific Medical College and Hospital, Udaipur, Rajasthan after ethical committee approval. Data regarding sex of the donor, type of donors and screening test results were collected from the records of blood bank over a period of 3 years (May 2014 - June 2016).

Result: Total 2015 donors were registered of which 1944 (96.5\%) were males and 71 (3.5\%) were females. Replacement donors (68.7\%) were more compared to voluntary donors $(31.3 \%)$. Overall prevalence of TTIs in our blood bank is $2.38 \%$ of which prevalence of Syphilis $(1.2 \%)$ was highest followed by HBV $(0.89 \%)$, HIV $(0.14 \%)$, and Malaria $(0.1 \%)$.

Conclusion: TTIs were more common in replacement donors than in voluntary donors, hence more voluntary donations need to be encouraged. Extensive donor screening by more sensitive methods to detect infections early can reduce the risk of TTIs.
\end{abstract}

Keywords: TTIs, Voluntary Donors, Replacement Donors, Blood Bank, HIV, HBV, HCV, Syphilis, Malaria.

\section{Introduction}

Banking of blood is important as it is one of the most precious commodities. Safe blood transfusion is of utmost importance as an unsafe blood transfusion bears lot of burden on human life and economy. Providing safe and adequate blood should be an integral part of every country's national health care policy and infrastructure. ${ }^{[1]}$ Amongst the blood transfusion complications, transmission of certain infections (TTIs) like HIV, Hepatitis B and C and Syphilis are most significant for the long term detrimental side effects. Meticulous pre-transfusion screening and testing particularly for transfusion transmissible infections (TTIs) is the need of the hour. ${ }^{[2]}$

India has a population of more than 1.2 billion with 5.7 million Human Immunodeficiency Virus (HIV) positive, 43 million HBV positive and 15 million HCV positive persons. The risk of transfusion transmission of these viruses may be alarming due to high seroprevalence of $\mathrm{HIV}, \mathrm{HCV}$, and $\mathrm{HBV}(0.5 \%, 0.4 \%$, and $1.4 \%$ respectively $)$ among the blood donors. ${ }^{[2]}$

Over period of time, availability of newer and more sensitive screening tests with strict implementation of testing rules has significantly reduced the incidence of TTIs in most developed countries while on the other hand, scenario in developing countries has not changed much. Poor health infrastructure, lack of health awareness in people, and failure to implement strict norms of screening result is increasing prevalence and incidence of the infections in the population. ${ }^{[3]}$

Thus the present study was carried out with an aim to assess the trend and seroprevalence of TTIs among blood donors at the blood bank attached to Pacific Medical College and Hospital, Udaipur, Rajasthan.

\section{Materials and Methods}

The present retrospective study was carried out at the blood bank attached to Pacific Medical College and Hospital, Udaipur, Rajasthan after approval from the ethical committee of our institute. Data over a period of 3 years (May 2014 - June 2016) was collected from the records of blood bank. All donors who donated blood at blood bank as well as at various blood donation camps organized by our blood bank were included in this study. Exclusion of donors for the blood donation was done as per NACO guidelines. The screening methods for the detection of TTIs 
at our blood bank is HIV - Tridot (immunoassay); HBV HEPACARD (for HbsAg detection : Immunoassay based on sandwich principle); HCV - Tridot (immunoassay); VDRL-ASPEN Syphilis Rapid test (qualitative membrane based immunoassay); and Malaria - Satya $2.0 \mathrm{Pf} / \mathrm{Pv}$ Malaria Antigen (Card test)

The confirmatory testing methods for the detection of TTIs at our blood bank is HIV (Erba Lisa HIV Gen 4); HBV (Erba Lisa SEN HbsAg); HCV (Erba Lisa HCV Gen 3)

Data regarding sex of the donor, type of donors, and screening tests results were collected and tabulated in MS excel sheet. Statistical analysis of the collected data was carried out.

\section{Result}

In the present study a total of 2015 donors donated blood in three years. Most of the donations 1384 (68.7\%) were replacement compared to $631(31.3 \%)$ voluntary donation (Table 1). When Sex wise distribution of the donors was studied, it was found that majority of the donors are males 1944 (96.5\%) and rest 71(3.5\%) were females (Table 2).

Overall seroprevalence of TTIs in our blood bank is $2.38 \%$. Table 3 shows the year wise proportion of different TTIs among blood donors. With respect to individual TTI, it was observed that Syphilis (26 cases, 1.29\%) was the most common infection among blood donors followed by HBV (17 cases, $0.84 \%$ ), HIV (3 cases, $0.15 \%$ ), and Malaria (2 cases, $0.09 \%$ ). None of the donor in our study was positive for $\mathrm{HCV}$.

When year wise prevalence trend of TTIs was plotted, it was found that peak prevalence for Syphilis was during the year $2014(2.36 \%)$ followed by decline in the year 2015 $(0.69 \%)$, and with slight upsurge during the year 2016 $(1.06 \%)$. With respect to HBV infection peak prevalence was noted during the year 2014 (1.09\%), then declining trend in the years $2015(0.83 \%)$ and $2016(1.06 \%)$. In case of HIV infection, the same was $0.18 \%$ during the year 2014 , nil in the year $2015(0 \%)$, followed by an upsurge in the year $2016(0.26 \%)$. However prevalence of malaria (0.28\%) was noted only in the year 2015 (Table 3, Figure 1 and 2).

The pattern of TTIs with respect to the type of donor is depicted in Table 4. Higher prevalence of TTIs was noted in replacement donors compared to voluntary donors. Even with respect to individual TTI, HBV $(0.72 \%)$ and Syphilis prevalence $(1.4 \%)$ was high among replacement donors (Table 4).

\section{Discussion}

TTIs threaten the safety of recipients and community as a whole and are a subject of real concern worldwide. ${ }^{[3]}$ Despite the pre-donation counseling and medical fitness test, the presence of TTIs is inevitable in blood donation since a person can transmit infection during its asymptomatic phase (window period), transfusion can contribute to an ever widening pool of infection in the population. ${ }^{[1]}$

In the present study, out of total donors, replacement donors constituted $68.7 \%$ and voluntary donors constituted $31.3 \%$. Similar predominance of replacement donors was noted in other studies ${ }^{[3-8]}$ while on the contrary, Sunderan $\mathrm{S}$ et $\mathrm{al}^{[1]}$, Bhattacharya $\mathrm{P}$ et $\mathrm{al}^{\left[{ }^{[9]}\right.}$, Shah $\mathrm{N}$ et $\mathrm{al}^{[10]}$ noted predominance of voluntary donors in their studies. Out of 2015 donations,

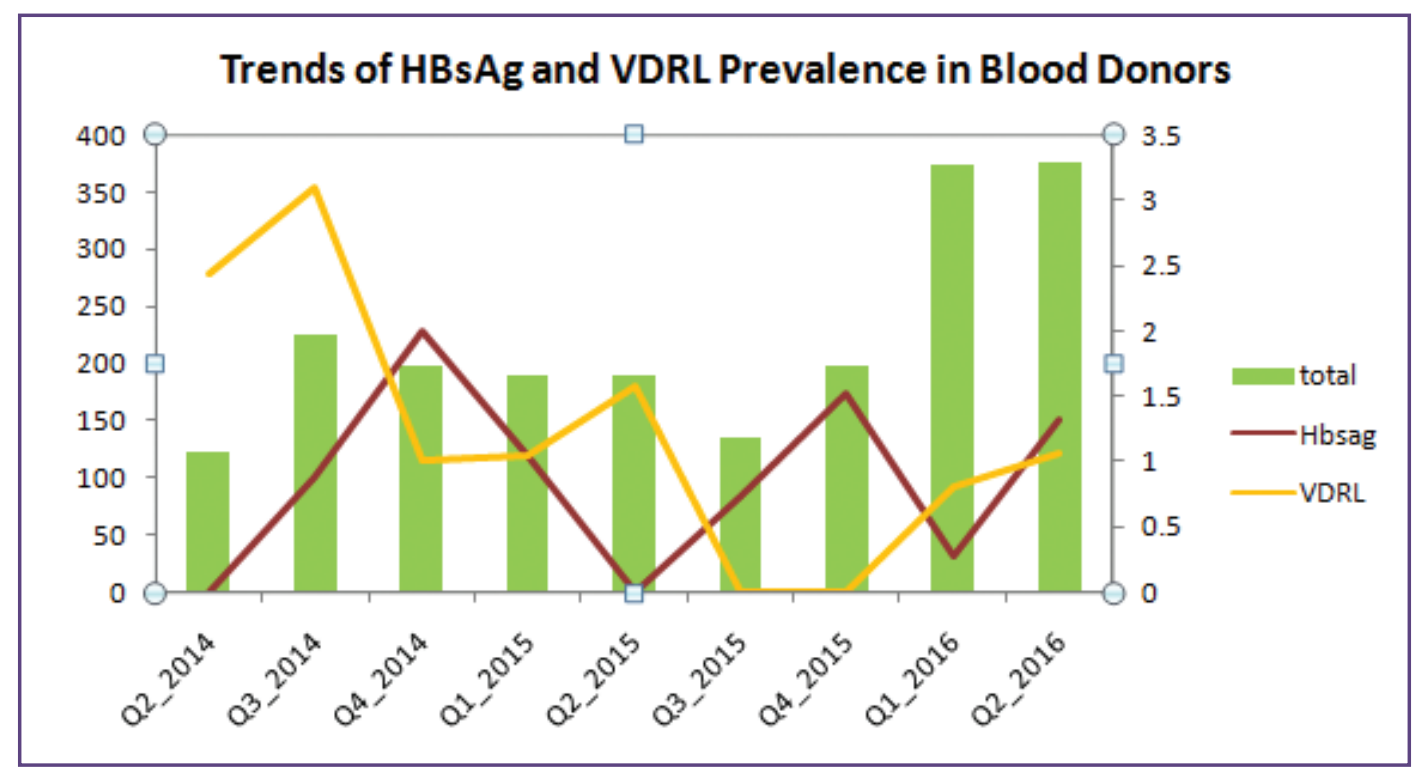

Fig. 1: Trends of HBV and Syphilis prevalence in Blood Donors. 


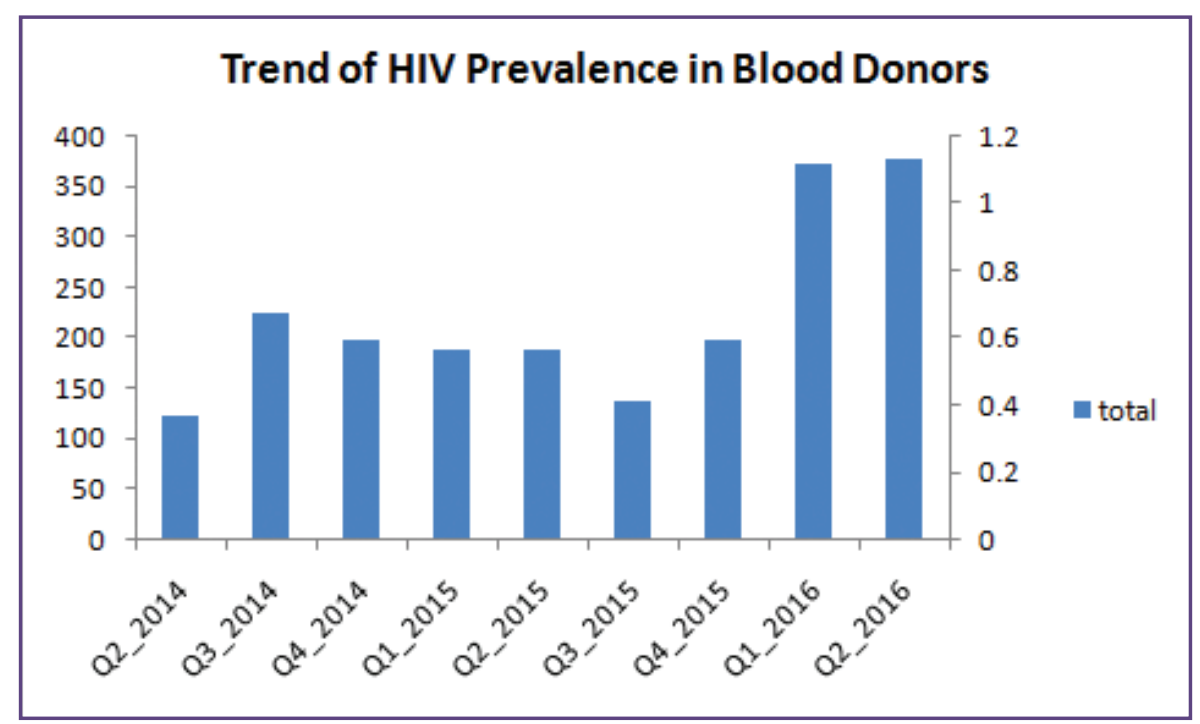

Fig. 2: Trend of HIV Prevalence in Blood Donors.

Table 1: Sex wise yearly distribution of blood donor types.

\begin{tabular}{|c|c|c|c|c|c|}
\hline & \multicolumn{2}{|c|}{ REPLACEMENT DONORS } & \multicolumn{2}{c|}{ VOLUNTARY DONORS } \\
\hline Year & Male & Female & Male & Female & 12 \\
\hline 2014 & 311 & 02 & 224 & 16 & 715 \\
\hline 2015 & 537 & 03 & 159 & 32 & 751 \\
\hline 2016 & 525 & 06 & $\mathbf{1 8 8}$ & $\mathbf{6 0}$ & $\mathbf{2 0 1 5}$ \\
\hline Total & $\mathbf{1 3 7 3}$ & $\mathbf{1 1}$ & $\mathbf{5 7 1}$ & & 715 \\
\hline
\end{tabular}

Table 2: Sex wise yearly distribution of all blood donors.

\begin{tabular}{|c|c|c|c|}
\hline Year & Male & Female & Total \\
\hline 2014 & 535 & 14 & 549 \\
\hline 2015 & 696 & 19 & 715 \\
\hline 2016 & 713 & 38 & 751 \\
\hline Total & 1944 & $\mathbf{7 1}$ & $\mathbf{2 0 1 5}$ \\
\hline
\end{tabular}

Table 3: Year wise Trends in Seroprevalence of TTIs.

\begin{tabular}{|c|c|c|c|c|c|}
\hline Year & HBV & HIV & VDRL & MP & Total \\
\hline 2014 & $06(1.09 \%)$ & $01(0.18 \%)$ & $13(2.36 \%)$ & 0 & 20 \\
\hline 2015 & $06(0.83 \%)$ & 0 & 05 (0.69\%) & $02(0.28 \%)$ & 13 \\
\hline 2016 & $05(0.66 \%)$ & $02(0.26 \%)$ & $08(1.06 \%)$ & 0 & 15 \\
\hline Total & $17(0.84 \%)$ & $03(0.15 \%)$ & $26(1.29 \%)$ & $02(0.09 \%)$ & 48 \\
\hline
\end{tabular}

Table 4: Prevalence of TTIs among Donors types

\begin{tabular}{|c|c|c|c|c|}
\hline Type of donation & HBV & HIV & Syphilis & MP \\
\hline Replacement $(2.52 \%)$ & $10(0.72 \%)$ & $03(0.21 \%)$ & $20(1.4 \%)$ & $02(0.14 \%)$ \\
\hline Voluntary $(2.06 \%)$ & $07(1.10 \%)$ & 0 & $06(0.95 \%)$ & 0 \\
\hline
\end{tabular}


males contributed to a larger percentage (96.5\%) compared to females $(3.5 \%)$, which is in concordance with the data given by a similar other study. ${ }^{[3]}$

Syphilis $(1.2 \%)$ was the most common TTI in the present study, which is in contrast to the data of other studies ${ }^{[1-5,}$ ${ }^{10-13]}$ where HBV was the most common TTI, and where as in the study by Kaur $\mathrm{H}$ et al ${ }^{[14]} \mathrm{HCV}$ was most the common TTI. None of the donor in our study was positive for HCV, but all other studies noted HCV prevalence of which Kaur $\mathrm{H}$ et al ${ }^{[14]}$ had reported the highest $\mathrm{HCV}$ prevalence $(1.79 \%)$. (Table 5)

In the present study, higher prevalence of TTIs was noted among replacement donors as compared to the voluntary donors, which is in concordance with the other studies..$^{[1,4}$,
6, 10-13, 15] Where as only Kakkar $\mathrm{N}$ et al ${ }^{[7]}$ reported marginally higher prevalence among voluntary donors.

In order to reduce the risk of these infections and to improve the blood safety, stringent measures need to be taken for the blood donor screening by using more sensitive methods to detect the infections early. Better screening methods are required to decrease the window period of TTIs for example testing of hepatitis B core antigen, along with the already existing Enzyme Linked Immunosorbent Assay (ELISA) tests for detection of hepatitis B surface antigen will aid in better detection of HBV. However, now with the advent of Nucleic Acid Amplification Techniques (NAT), western countries have decreased the risk of TTIs to a major extent. NAT has added benefits but its high cost is of concern especially in developing countries like India.

Table 5: Seroprevalence of individual TTIs among different studies.

\begin{tabular}{|c|c|c|c|c|c|}
\hline Studies & HBV & HIV & HCV & Syphilis & Malaria \\
\hline Sunderam S et al[ ${ }^{[1]}$ & $1.01 \%$ & $0.08 \%$ & $0.14 \%$ & $0.03 \%$ & $0.33 \%$ \\
\hline Shaikh M et al| ${ }^{[2]}$ & $2.21 \%$ & $0.51 \%$ & $1.11 \%$ & $0.17 \%$ & 0 \\
\hline Yadav BS et al[3] & $1.77 \%$ & $0.14 \%$ & $0.09 \%$ & $0.04 \%$ & 0 \\
\hline Arora D et al ${ }^{[4]}$ & $1.7 \%$ & $0.3 \%$ & $1.0 \%$ & $0.9 \%$ & 0 \\
\hline Pahuja S et al[5] & $2.23 \%$ & $0.56 \%$ & $0.66 \%$ & - & - \\
\hline Shah $\mathrm{N}$ et al[10] & $0.97 \%$ & $0.16 \%$ & $0.10 \%$ & $0.23 \%$ & 0 \\
\hline Mandal R et al[11] & $1.24 \%$ & $0.42 \%$ & $0.62 \%$ & $0.65 \%$ & $0.004 \%$ \\
\hline Philip CJ et al ${ }^{[12]}$ & $1.7 \%$ & $0.7 \%$ & $0.3 \%$ & - & - \\
\hline Pallavi P et al[13] & $1.27 \%$ & $0.44 \%$ & $0.23 \%$ & $0.28 \%$ & 0 \\
\hline Kaur $\mathrm{H}$ et a[ ${ }^{[14]}$ & $0.75 \%$ & $0.16 \%$ & $1.79 \%$ & $0.67 \%$ & 0 \\
\hline Fernandes $\mathrm{H}$ et al ${ }^{[15]}$ & $0.34 \%$ & $0.06 \%$ & $0.06 \%$ & $0.11 \%$ & $0.01 \%$ \\
\hline Present Study & $0.84 \%$ & $0.15 \%$ & 0 & $1.29 \%$ & $0.09 \%$ \\
\hline
\end{tabular}

\section{Conclusion}

To conclude, overall seroprevalence of TTIs in our study is $2.38 \%$ with Syphilis being the most common TTI. TTIs were more common in replacement donors as compared to the voluntary donors implying that voluntary donations are more safer. Hence more voluntary donations need to be encouraged. Extensive donor screening by more sensitive methods to detect infections early can reduce the risk of TTIs.

The major limitation of our study is that there was no previous data available from Rajasthan for comparison and analysis of trends. Hence, we recommend for future studies with larger sample size to look into the trends of TTIs from this geographical area.

\section{Acknowledgements}

The authors wish to acknowledge the help received from our blood bank staff Mr Tejpal Chauhan and Mr Ganesh

\section{Reference}

1. Sunderam S, Karir S, Haider S, Singh SB, Kiran A. Seroprevalence of Transfusion Transmitted infections among blood donors at Blood Bank of Rajendra Institute of Medical Sciences, Ranchi. Healthline Journal 2015; 6(1): 36-40.

2. Shaikh M, Bhople KS. Seroprevalence of Transfusion Transmitted infections in blood donors at a rural based tertiary care teaching hospital in India. IOSR Journal of Dental and Medical Sciences 2015; 14(10): 29-32.

3. Yadav BS, Varma AV, Singh P, Kumar R, Bandi PK. Seroprevalence of Transfusion-transmitted infections (TTIs) in blood donors: A study from Central India. Int J Med Sci Public Health 2016; 5(6): 1-5.

4. Arora D, Arora B, Khetarpal A. Seroprevalence of HIV, $\mathrm{HBV}, \mathrm{HCV}$ and syphilis in blood donors in Southern Haryana. Indian J Pathol Microbiol 2010; 53: 308-309.

5. Pahuja S, Sharma M, Baitha B, Jain M. Prevalence and trends of markers of hepatitis $\mathrm{C}$ virus, hepatitis $\mathrm{B}$ virus and 
HIV in Delhi blood donors: A hospital based study. JP J Inf Dis 2007; 60: 389-91.

6. Singh B, Verma M, Kotru M, Verma K, Batra M. Prevalence of HIV and VDRL seropositivity in blood donors of Delhi. Indian J Med Res 2005; 122: 234-36.

7. Kakkar N, Kaur R, Dhanoa J. Voluntary donors need for a second look. Indian J Pathol Microbiol 2004; 47: 381-83.

8. Khageshan AP, Kulkarni KR, Baragundi MC. Seroprevalence of Co-infections among blood donors in a blood bank of a tertiary care health centre. APALM 2016; 3(1): A29-32.

9. Bhattacharya P, Chakraborty S, Basu SK. Significant increase in HBV, HCV, HIV and syphilis infections among blood donors in West Bengal Eastern India 2004-2005. Exploratory screening reveals high frequency of occult HBV infection. World J Gastroenterol 2007; 13: 3730-3733.

10. Shah N, Shah JM, Jhaveri P, Patel K, Shah CK, Shah NR. Seroprevalence of HBV, HCV, HIV and syphilis among blood donors at a tertiary care teaching hospital in Western India. Gujarat Medical Journal 2013; 68(2): 35-39.

11. Mandal R, Mondal K. Transfusion Transmissible infections among blood donors from a sub-Himalayan rural tertiary care centre in Darjeeling, India. Journal of Traditional and Complementary Medicine 2015; 1-6.

12. Philip J, Sarkar RS, Kumar S, Pathak A. Changing trends of Transfusion transmitted viral infections among blood donors in the last decade - A 10 year study in a large tertiary care blood bank (2000-2009). MJAFI 2015; 68(1): 28-32.

13. Pallavi P, Ganesh CK, Jayshree K, Manjunath GV. Seroprevalence and trends in Transfusion Transmitted Infections among blood donors in a university hospital blood bank - A 5 year study. Indian J Hematol Blood Transfus 2011 Mar; 27(1): 1-6.

14. Kaur H, Mannan R, Manjari M. Seroprevalence of the blood borne infections in blood donors: Our 11 year (2001-2011) experience in a tertiary care teaching hospital at Amritsar (Punjab). International Journal of Advanced Research 2014; 2(6): 967-71.

15. Fernandes H, D'Souza PF, D'Souza PM. Prevalence of Transfusion Transmitted Infections in voluntary and replacement Donors. Indian J Hematol Blood Transfus 2010; 26(3): 89-91.

*Corresponding author:

Dr. Preeti Agrawal, 174A/P Road, Bhupalpura, Udaipur, Rajasthan, 313001 India.

Phone: +91 8854801375

Email: preetibagrawal79@gmail.com

Date of Submission : 07.10.2016

Financial or other Competing Interests: None. 